Research Article

\title{
FTIR and EPR Studies of Nickel Substituted Nanostructured Mn Zn Ferrite
}

\author{
C. Venkataraju and R. Paulsingh \\ Karpaga Vinayaga College of Engineering and Technology, Madurantakam 603308, India \\ Correspondence should be addressed to C. Venkataraju; venkatarajuc40@gmail.com
}

Received 15 July 2014; Revised 12 August 2014; Accepted 12 August 2014; Published 22 September 2014

Academic Editor: Yiqian Wang

Copyright (C) 2014 C. Venkataraju and R. Paulsingh. This is an open access article distributed under the Creative Commons Attribution License, which permits unrestricted use, distribution, and reproduction in any medium, provided the original work is properly cited.

\begin{abstract}
The spinel ferrite system $\mathrm{Mn}_{0.5-x} \mathrm{Ni}_{x} \mathrm{Zn}_{0.5} \mathrm{Fe}_{2} \mathrm{O}_{4}$ is prepared by coprecipitation method. XRD analysis confirms the formation of ferrite phase in all the samples. The FTIR spectra of all the samples show two main absorption bands below $1000 \mathrm{~cm}^{-1}$. FTIR studies reveal cationic exchange between A site and B site. The magnetic moment calculated from EPR studies is lower when compared to the theoretical values. This confirms the existence of noncollinear magnetic structure arising due to spin canting at B site.
\end{abstract}

\section{Introduction}

Manganese zinc ferrite is technologically important class of materials because of its unusual magnetic properties and is extensively used in electronic applications such as transformers, coils, and recording heads. Ferrites crystallize into spinal type which has tetrahedral A site and octahedral $B$ site. The properties of the ferrites can be tuned by varying the cation and their distribution among tetrahedral A site and octahedral B site. Further bulk properties of ferrite change as its dimensions are changed to nanoscale [1-4]. Superparamagnetism, spin canting, and metastable cation distribution are some of the phenomena which have been observed in nanoparticles of various ferrites.

The method of preparation plays an important role in the properties of the ferrite nanoparticles. Varieties of experimental methods like sol-gel method, coprecipitation method, hydrothermal method, reverse micelle method, and autocombustion method are carried out for the production of ferrite nanoparticles. Among these methods coprecipitation method is an attractive method for producing nanoferrites because of increased homogeneity, purity, and reactivity. Singh et al. [5] have reported the EPR studies of nanostructured zinc ferrites heat treated at different temperature. Priyadharsini et al. [6] have reported the FTIR studies of nanostructured NiZn ferrite. In the present investigation we report the FTIR, EPR studies of the Ni substituted MnZn ferrite nanoparticles prepared by coprecipitation method.

\section{Experimental Details}

Nanoparticles of $\mathrm{Mn}_{(0.5-x)} \mathrm{Ni}_{x} \mathrm{Zn}_{0.5} \mathrm{Fe}_{2} \mathrm{O}_{4}$ with $x$ varying from 0.0 to 0.3 were prepared by coprecipitation method. Aqueous solutions of $\mathrm{MnCl}_{2}, \mathrm{ZnSo}_{4}, \mathrm{NiCl}_{2}$, and $\mathrm{FeCl}_{3}$ in their respective stoichiometry were thoroughly mixed at $80^{\circ} \mathrm{C}$. This mixture was then transferred immediately into a boiling solution of $\mathrm{NaOH}$ at $100^{\circ} \mathrm{C}$. Precipitation takes place and the solution was stirred for about 60 minutes until the reaction is complete. The $\mathrm{pH}$ of the solution was maintained at 12 throughout the reaction. Conversion of metal salts into hydroxides and subsequent transformation of metal hydroxide to nanoferrites takes place. The nanoparticles thus formed were isolated by centrifugation and washed several times with deionized water followed by acetone and then dried at room temperature. The dried powder was grounded thoroughly in a clean agate mortar. Obtained powders were used for all of the measurements. X-ray diffraction (XRD) was carried out using a PANanalytical X'pert PRO diffractometer using $\mathrm{CuK} \alpha$ as radiation source. Data were collected for every $0.02^{\circ}$ in the angle range $20^{\circ}-70^{\circ}$ of $2 \theta$. Scanning electron microscope imaging was carried out using the FEI Quanta FEG 200 

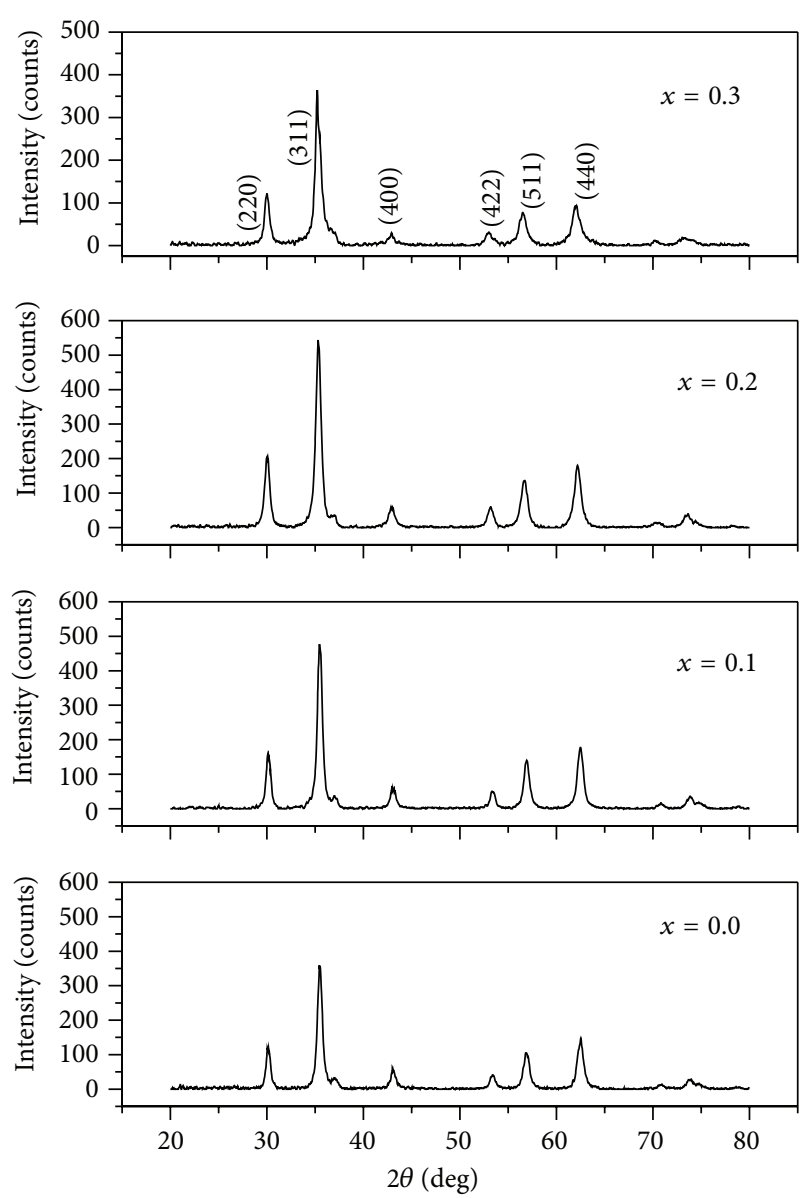

FIGURE 1: X-ray diffraction pattern for $\mathrm{Mn}_{0.5-x} \mathrm{Ni}_{x} \mathrm{Zn}_{0.5} \mathrm{Fe}_{2} \mathrm{O}_{4}(x=$ $0.0,0.1,0.2,0.3)$.

(HR-SEM) equipment for the surface morphology analysis. The particle size was determined by subjecting the samples to transmission electron microscopy (TEM) using a Phillips CM20 microscope. The Fourier transform infrared (FTIR) spectra were recorded in the range $400 \mathrm{~cm}^{-1}$ to $4000 \mathrm{~cm}^{-1}$ using a FTIR spectrometer (Bruker). Electron paramagnetic resonance (EPR) spectra were taken by using an X-band CW EPR (EMX 102.7) spectrometer.

\section{Results and Discussion}

3.1. Structural Analysis. Figure 1 shows the $\mathrm{X}$-ray diffraction pattern for $\mathrm{Mn}_{(0.5-x)} \mathrm{Ni}_{x} \mathrm{Zn}_{0.5} \mathrm{Fe}_{2} \mathrm{O}_{4}$ (with $x=0.0,0.1$, $0.2,0.3)$. The diffraction pattern confirmed the formation of cubic ferrite phase for all the samples. The broad XRD line indicates that the ferrite particles are of nanosize. The average crystalline size for each composition is calculated from XRD line width of (311) peak using Scherrer formulae [7] and is given in Table 1. Figure 2 shows the TEM image of $\mathrm{Mn}_{(0.5-x)} \mathrm{Ni}_{x} \mathrm{Zn}_{0.5} \mathrm{Fe}_{2} \mathrm{O}_{4}$. It is observed that all the samples are highly homogeneous and nearly spherical in shape. Figure 3 shows the SEM image of $\mathrm{Mn}_{(0.5-x)} \mathrm{Ni}_{x} \mathrm{Zn}_{0.5} \mathrm{Fe}_{2} \mathrm{O}_{4}$. A clear SEM image reveals that there are no secondary phases. This
TABLE 1: Particle size for the sample $\mathrm{Mn}_{0.5-x} \mathrm{Ni}_{x} \mathrm{Zn}_{0.5} \mathrm{Fe}_{2} \mathrm{O}_{4}$ (with $x=$ $0.0,0.1,0.2$, and 0.3 )

\begin{tabular}{cccc}
\hline$x$ & Composition & $\begin{array}{c}\text { Crystallite size } \\
(\mathrm{nm})\end{array}$ & $\begin{array}{c}\text { Particle size } \\
(\mathrm{nm})\end{array}$ \\
\hline 0.0 & $\mathrm{Mn}_{0.5} \mathrm{Zn}_{0.5} \mathrm{Fe}_{2} \mathrm{O}_{4}$ & 14 & TEM \\
0.1 & $\mathrm{Mn}_{0.4} \mathrm{Ni}_{0.1} \mathrm{Zn}_{0.5} \mathrm{Fe}_{2} \mathrm{O}_{4}$ & 13.5 & 19 \\
0.2 & $\mathrm{Mn}_{0.3} \mathrm{Ni}_{0.2} \mathrm{Zn}_{0.5} \mathrm{Fe}_{2} \mathrm{O}_{4}$ & 14 & 18 \\
0.3 & $\mathrm{Mn}_{0.2} \mathrm{Ni}_{0.3} \mathrm{Zn}_{0.5} \mathrm{Fe}_{2} \mathrm{O}_{4}$ & 15.2 & 17 \\
\hline
\end{tabular}

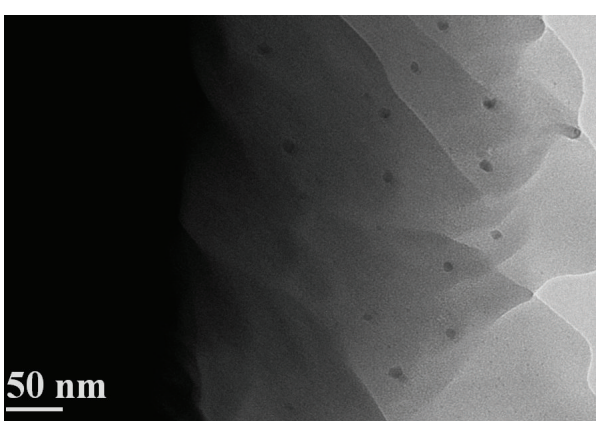

Figure 2: TEM image of $\mathrm{Mn}_{0.5} \mathrm{Zn}_{0.3} \mathrm{Ni}_{0.2} \mathrm{Fe}_{2} \mathrm{O}_{4}$.

is supported by the absence of additional peaks in the XRD pattern.

3.2. FTIR Studies. Figure 4 shows the room temperature IR spectrum of the above mentioned samples. The spectra are recorded in the range 400 to $4000 \mathrm{~cm}^{-1}$. The spectra show two main absorption band below $1000 \mathrm{~cm}^{-1}$ which is a common feature of ferrites. The high frequency band $v_{1}$ lies in the range $560-600 \mathrm{~cm}^{-1}$ while the low frequency band lies in the range $474-436 \mathrm{~cm}^{-1}$. These bands are assigned to the vibrations of the metal ion-oxygen complexes in tetrahedral and octahedral sites, respectively $[8,9]$. It is observed that the high frequency band $v_{1}$ increases with increase in $\mathrm{Ni}$ substitution, whereas the low frequency band $v_{2}$ is found to decrease. Waldron [9] attributed the high frequency band $v_{1}$ to the intrinsic vibrations of the tetrahedral groups and the low frequency band to the octahedral groups. Puri and Varshney [10] have reported that $\mathrm{Zn}^{2+}$ showed a strong preference for tetrahedral $\mathrm{A}$ site and $\mathrm{Ni}^{2+}$ ion showed preference for $\mathrm{B}$ site, while $\mathrm{Mn}^{2+}$ ions showed preference for A site and B site. We have also observed from our earlier studies [11] that $\mathrm{Ni}^{2+}$ ions occupy the $\mathrm{B}$ site and force some of the $\mathrm{Fe}^{3+}$ ions from $\mathrm{B}$ site to $\mathrm{A}$ site. $\mathrm{Ni}^{2+}$ ions in the octahedral site have larger ionic radius and higher atomic weight than $\mathrm{Fe}^{3+}$ ions. This affects the $\mathrm{Fe}^{3+}-\mathrm{O}^{2-}$ stretching vibration resulting in the decrease of octahedral vibrational frequency. This may be the reasons for the increase in the octahedral peak intensity. The increase in the concentration of $\mathrm{Fe}^{3+}$ ions having lower ionic radius and lower atomic weight in the tetrahedral site increases the tetrahedral frequency vibration. All our samples show a split in the octahedral frequency band. Priyadarsini et al. [6] have obtained similar split in the octahedral frequency band. 


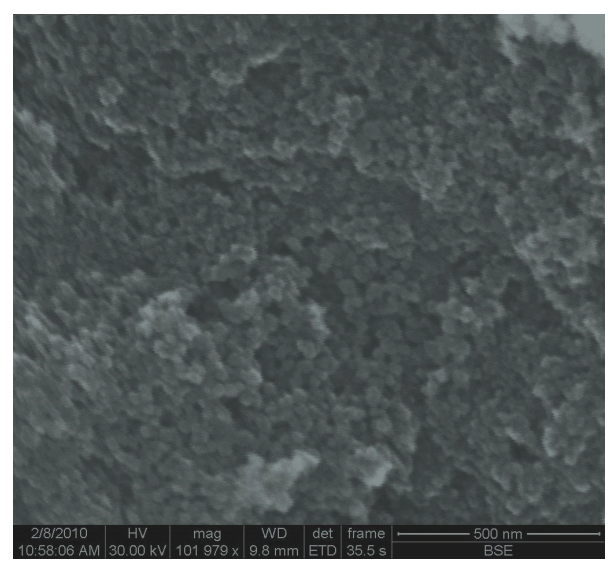

Figure 3: SEM image of $\mathrm{Mn}_{0.5} \mathrm{Zn}_{0.3} \mathrm{Ni}_{0.2} \mathrm{Fe}_{2} \mathrm{O}_{4}$.
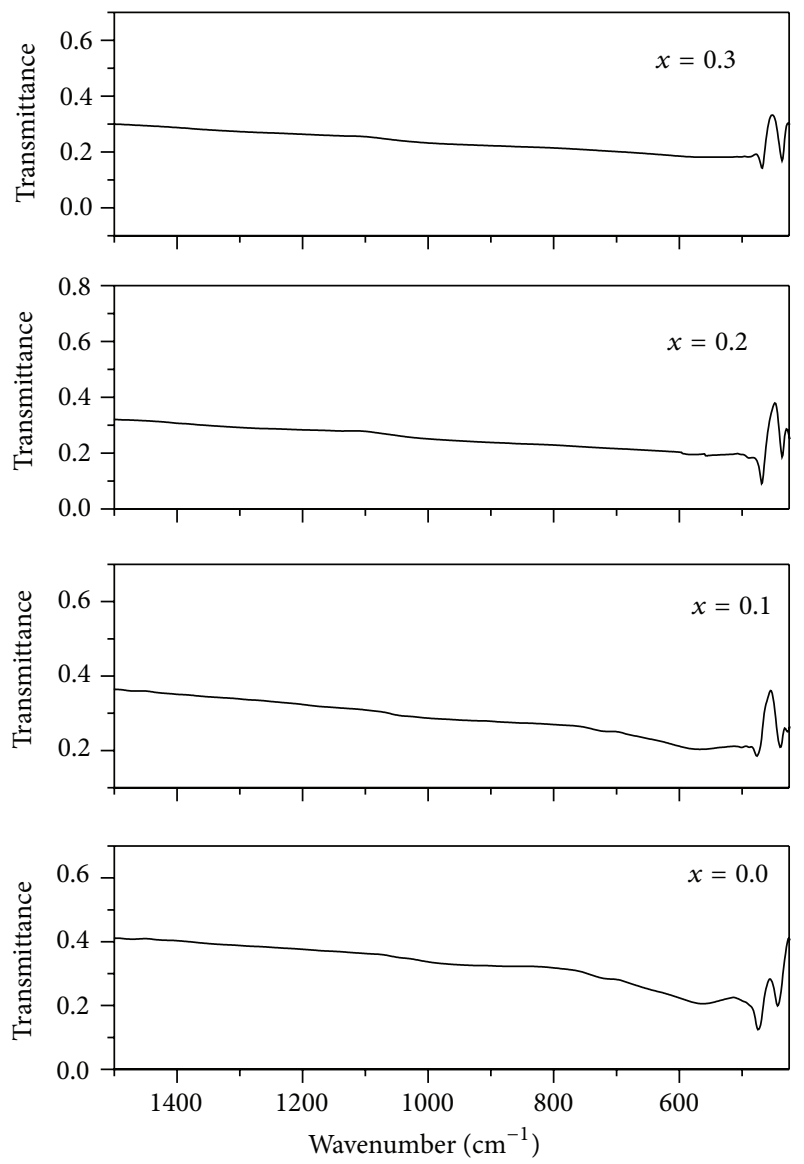

FIGURE 4: FTIR spectra of $\mathrm{Mn}_{0.5-x} \mathrm{Ni}_{x} \mathrm{Zn}_{0.5} \mathrm{Fe}_{2} \mathrm{O}_{4}(x=0.0,0.1,0.2$, $0.3)$.

3.3. EPR Spectral Studies. The EPR of ferrite is important for investigating the magnetic properties of magnetic materials at high frequency because the resonance originates from the interaction between spin and electromagnetic waves. The powder EPR spectra of $\mathrm{Mn}_{(0.5-x)} \mathrm{Ni}_{x} \mathrm{Zn}_{0.5} \mathrm{Fe}_{2} \mathrm{O}_{4}$ (with $x=0.0,0.1,0.2,0.3)$ were measured at $9.3 \mathrm{GHz}$ at room temperature and are shown in Figure 5. The resonance line
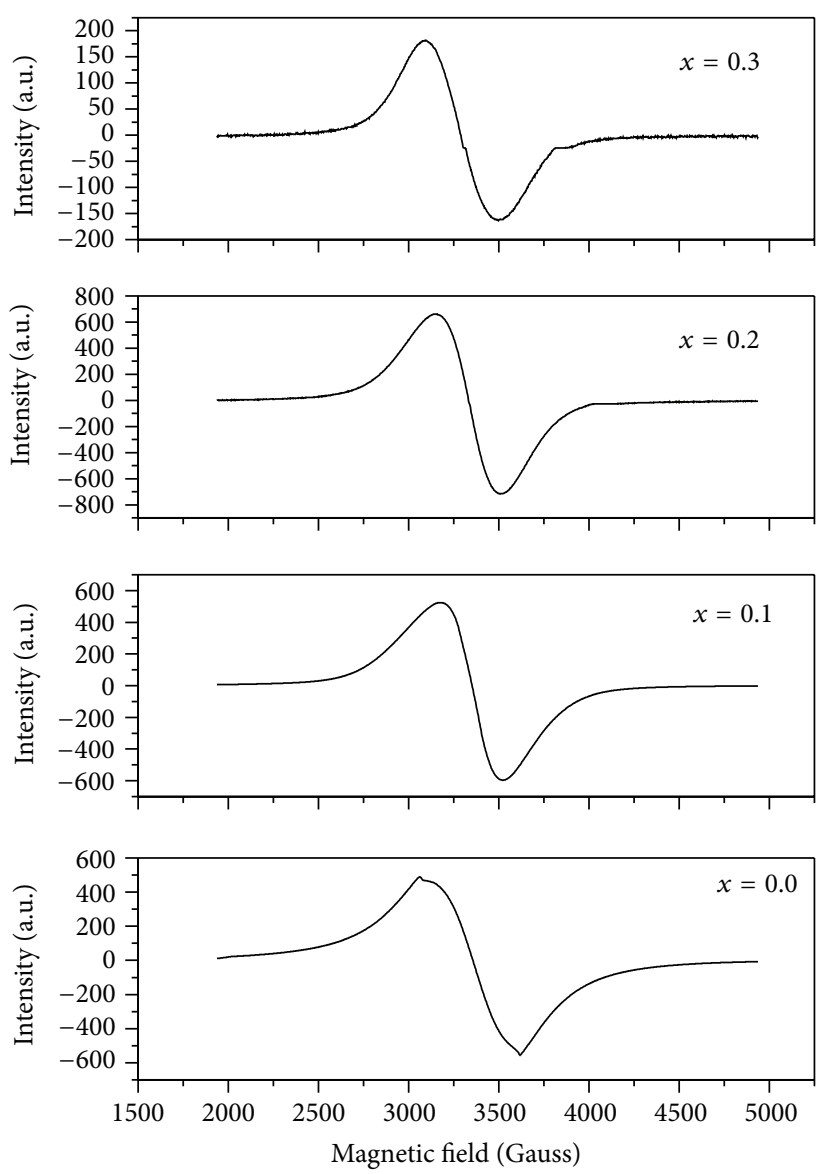

FIGURE 5: EPR spectra for $\mathrm{Mn}_{0.5-x} \mathrm{Ni}_{x} \mathrm{Zn}_{0.5} \mathrm{Fe}_{2} \mathrm{O}_{4}(x=0.0,0.1,0.2$, $0.3)$.

width $(\Delta H)$, the position corresponding to zero signal $\left(H_{0}\right)$, and the effective $g$ factor are determined from [12-14]

$$
g=\frac{h v}{\beta H},
$$

where $h$ is the planck's constant, $v$ is the frequency of the microwave, $H$ is the magnetic field occurring, and $\beta$ is the Bohr magneton. From Table 2 it was observed that the $g$ value decreased with increasing Ni substitution up to $x=0.2$ and then increases for $x=0.3$. This decrease in the value of $g$ may be due to superexchange interaction between $\mathrm{Ni}^{2+}$ and $\mathrm{Fe}^{3+}$ ions through nonmagnetic $\mathrm{O}^{2-}$ ions. Due to decrease in the superexchange interaction there may be rise in the value of $g$ for the substitution $x=0.3$. The superexchange interaction in ferrite is responsible for magnetic ordering within each sublattice. The interaction between $\mathrm{A}$ and $\mathrm{B}$ site is strongest in ferrites. As the $\mathrm{AB}$ interaction predominate, the spins of $A$ and $B$ site ions in ferrites will be opposite with a resultant magnetic moment equal to the difference between those of $\mathrm{A}$ and $\mathrm{B}$ site ions [15-17].

The theoretical values of the magnetic moment per formula unit and the experimental values of the magnetic moment are given in Table 2. According to the cation distribution estimated from our earlier studies, it was observed 
TABLE 2: EPR parameters for the system $\mathrm{Mn}_{0.5-x} \mathrm{Ni}_{x} \mathrm{Zn}_{0.5} \mathrm{Fe}_{2} \mathrm{O}_{4}(x=0.0,0.1,0.2$, and 0.3$)$.

\begin{tabular}{ccccccc}
\hline$x$ & Composition & $\begin{array}{c}\Delta \mathrm{Hpp} \\
\text { Gauss }\end{array}$ & $\begin{array}{c}\text { Resonance } \\
\text { field (B) } \\
\text { Gauss }\end{array}$ & $g_{\text {eff }}$ & $\begin{array}{c}\text { Magnetic } \\
\text { moment } \\
\mu \text { (exp.) }\end{array}$ & $\begin{array}{c}\text { Magnetic } \\
\text { moment } \\
\mu(\text { theo.) }\end{array}$ \\
\hline 0.0 & $\mathrm{Mn}_{0.5} \mathrm{Zn}_{0.5} \mathrm{Fe}_{2} \mathrm{O}_{4}$ & 537 & 3341 & 2.031 & 3.386 & 5.14 \\
0.1 & $\mathrm{Mn}_{0.4} \mathrm{Ni}_{0.1} \mathrm{Zn}_{0.5} \mathrm{Fe}_{2} \mathrm{O}_{4}$ & 349 & 3345 & 2.030 & 3.382 & 5.12 \\
0.2 & $\mathrm{Mn}_{0.3} \mathrm{Ni}_{0.2} \mathrm{Zn}_{0.5} \mathrm{Fe}_{2} \mathrm{O}_{4}$ & 346 & 3346 & 2.029 & 3.381 & 5.11 \\
0.3 & $\mathrm{Mn}_{0.2} \mathrm{Ni}_{0.3} \mathrm{Zn}_{0.5} \mathrm{Fe}_{2} \mathrm{O}_{4}$ & 394 & 3280 & 2.069 & 3.449 \\
\hline
\end{tabular}

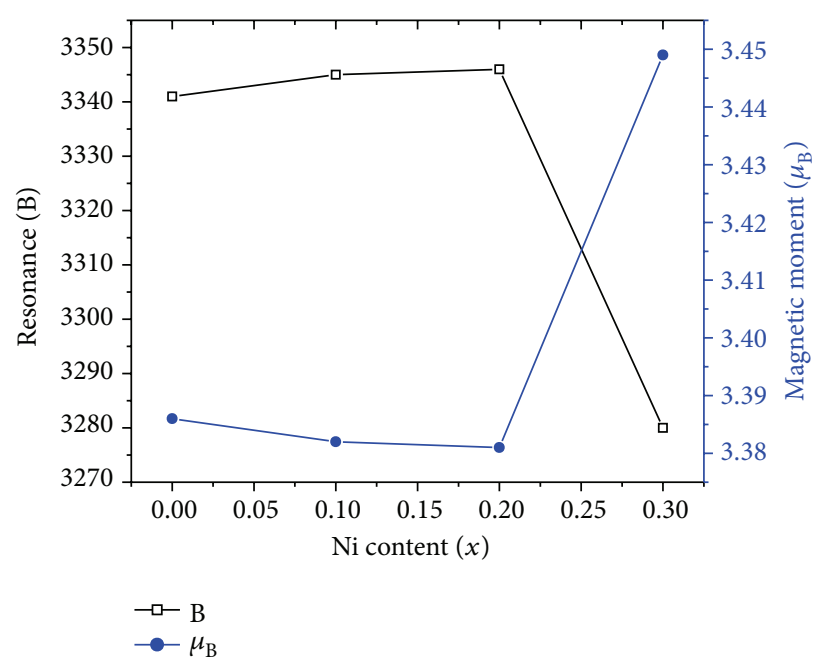

Figure 6: Relation between magnetic moment $(\mu)$ and the resonance field $\left(H_{R}\right)$ as a function of Ni content.

that the net magnetic moment of $\mathrm{Mn}_{(0.5-x)} \mathrm{Ni}_{x} \mathrm{Zn}_{0.5} \mathrm{Fe}_{2} \mathrm{O}_{4}$ is $5.14 \mu_{\mathrm{B}}$ but the experimental value of the total magnetic moment is $3.38 \mu_{\mathrm{B}}$. This low value of experimental values may be due to the occupation of $\mathrm{Ni}^{2+}$ ions in the $\mathrm{B}$ site. This forces some of the $\mathrm{Fe}^{3+}$ ions from $\mathrm{B}$ site to A site. As a result of this migration of ions between $A$ and $B$ site, the magnetization at $B$ site decreases resulting in overall decrease in the magnetization of the samples. In addition to this rearrangement of cation between A site and B site, the other reasons reported in literature are due to significant canting existing in B site $[18,19]$. Surface effects and the occurrence of a glassy state were also reported to be playing an active role in the decline of magnetic value [20].

Figure 6 shows the relation between magnetic moment and the resonance field $H_{R}$ as a function of Ni substitution. The resonance field $H_{R}$ increases with increase in the $\mathrm{Ni}$ content and reaches a maximum for the sample $x=0.2$, whereas the magnetic moment decreases with increasing $\mathrm{Ni}$ content. This can be attributed to the reason that as the magnetic moment decreases the internal field also decreases. So to satisfy the relation $\omega=\nu H$, the resonance field should be high.

Figure 7 shows the variation of line width with Ni content. The line width decreases with increase in the $\mathrm{Ni}$ content

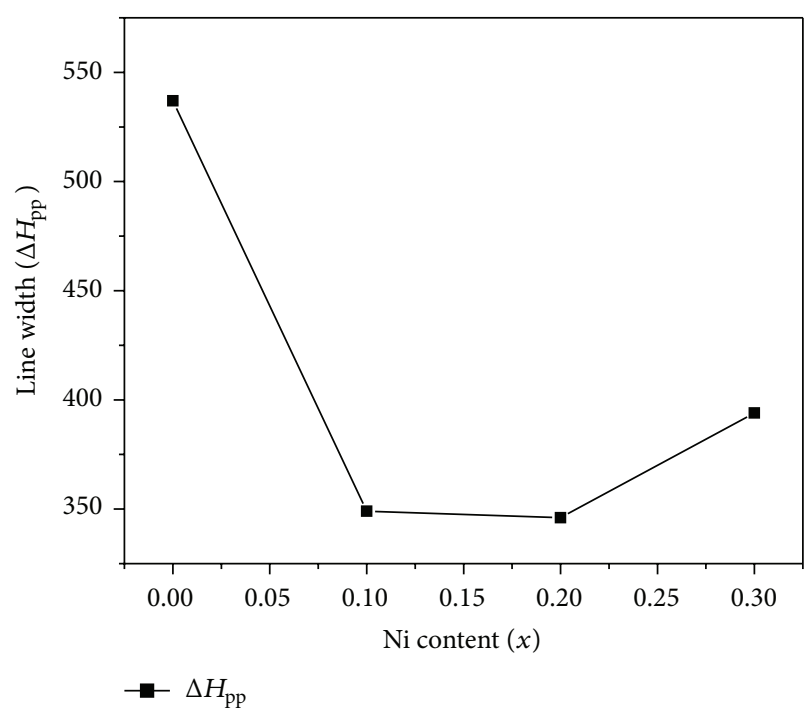

FIGURE 7: Variation of line width with Ni content.

upto $x=0.2$. This is due to occupation of $\mathrm{Ni}^{2+}$ ion in the octahedral B site. The presence of $\mathrm{Ni}^{2+}$ ions in the octahedral $B$ site causes a decrease in the magnetic moment of the B sublattice. This causes an overall decrease in the total magnetic moment. This decrease in the magnetic moment of the samples may be the reason for the decrease in the line width of the samples up to $x=0.2$.

\section{Conclusion}

Ni substituted MnZn nanoferrites were prepared by coprecipitation method. The X-ray diffraction pattern shows the formation of ferrite phase in all the samples. FTIR studies reveal cationic exchange between $\mathrm{A}$ site and $\mathrm{B}$ site. The line width decreases with increase in $\mathrm{Ni}$ content. Low experimental value of magnetic moment calculated from EPR spectra compared to the theoretical value confirms the existence of spin canting in B site which results in a noncollinear magnetic structure.

\section{Conflict of Interests}

The authors declare that there is no conflict of interests regarding the publication of this paper. 


\section{References}

[1] J. M. D. Coey and K. Khalafella, "Superparamagnetic $\mathrm{Y}-\mathrm{Fe}_{2} \mathrm{O}_{4}$," Physica Status Solidi A, vol. 11, pp. 225-241, 1972.

[2] H. S. Nalwa, Ed., Magnetic Nanostructure, chapter 1-4, American Scientific Publishers, Stevenson Ranch, Calif, USA, 2002.

[3] M. Sorescu, L. Diamandescu, P. D. Ramesh, R. Roy, A. Daly, and Z. Bruno, "Evidence for microwave-induced recrystallization in NiZn ferrites," Materials Chemistry and Physics, vol. 101, no. 2-3, pp. 410-414, 2007.

[4] W. A. De Hoer, "Nanomagnetism," in Characterization of Nanophase Materials, Z. I. Wang, Ed., Wiley-VCH, Weinheim, Germany, 2000.

[5] J. P. Singh, R. C. Srivastava, H. M. Agrawal, R. P. S. Kushwaha, P. Chand, and R. Kumar, "EPR study of nanostructured zinc ferrite," International Journal of Nanoscience, vol. 7, no. 1, pp. 2127, 2008.

[6] P. Priyadharsini, A. Pradeep, P. S. Rao, and G. Chandrasekaran, "Structural, spectroscopic and magnetic study of nanocrystalline Ni-Zn ferrites," Materials Chemistry and Physics, vol. 116, no. 1, pp. 207-213, 2009.

[7] R. D. Cullity, Elements of X-Ray Diffraction, Addision-Wesley, 1996.

[8] M. Kaiser, "Effect of preparation condition on nickel zinc ferrite nanoparticle: a comparison between sol-gel," Journal of Alloys and Compounds, vol. 468, no. 1-2, pp. 15-21, 2009.

[9] R. D. Waldron, "Infrared spectra of ferrites," Physical Review, vol. 99, no. 6, pp. 1727-1735, 1955.

[10] R. K. Puri and U. Varshney, "Mössbauer study of $\mathrm{Zn}^{2+}$ and $\mathrm{Sn}^{4+}$ additives in Nickel ferrites," Journal of Physics and Chemistry of Solids, vol. 44, no. 7, pp. 655-661, 1983.

[11] C. Venkataraju, G. Sathishkumar, and K. Sivakumar, "Effect of cation distribution on the structural and magnetic properties of nickel substituted nanosized $\mathrm{Mn}-\mathrm{Zn}$ ferrites prepared by co-precipitation method," Journal of Magnetism and Magnetic Materials, vol. 322, no. 2, pp. 230-233, 2010.

[12] K. V. P. M. Shafi, A. Gedanken, R. Prozorov, and J. Balogh, "Sonochemical preparation and size dependent properties of nanostructured $\mathrm{CoFe}_{2} \mathrm{O}_{4}$ particles," Chemistry of Materials, vol. 10, no. 11, pp. 3445-3450, 1998.

[13] M. R. Diehl, J.-Y. Yu, J. R. Heath et al., "Crystalline, shape, and surface anisotropy in two crystal morphologies of superparamagnetic cobalt nanoparticles by ferromagnetic resonance," Journal of Physical Chemistry B, vol. 105, no. 33, pp. 7913-7919, 2001.

[14] X. Cao and L. Gu, "Spindly cobalt ferrite nanocrystals: preparation, characterization and magnetic properties," Nanotechnology, vol. 16, no. 2, pp. 180-185, 2005.

[15] M. A. Willard, Y. Nakamura, D. E. Laughlin, and M. E. McHenry, "Magnetic properties of ordered and disordered spinel-phase ferrimagnets," Journal of the American Ceramic Society, vol. 82, no. 12, pp. 3342-3346, 1999.

[16] J. Smith and H. P. J. Wijn, Ferrites, Philips Technical Library, Eindhoven, The Netherlands, 1959.

[17] K. J. Standley, Oxide Magnetic Materials, Claredon Press, Oxford, UK, 1972.

[18] J. M. D. Coey, "Noncollinear spin arrangement in ultrafine ferrimagnetic crystallites," Physical Review Letters, vol. 27, no. 17, pp. 1140-1142, 1971.

[19] Q. A. Pankhurst and R. J. Pollard, "Origin of the spin-canting anomaly in small ferrimagnetic particles," Physical Review Letters, vol. 67, no. 2, pp. 248-250, 1991.
[20] M. G. del Muro, X. Batlle, and A. Labarta, "Erasing the glassy state in magnetic fine particles," Physical Review B: Condensed Matter and Materials Physics, vol. 59, no. 21, pp. 13584-13587, 1999. 

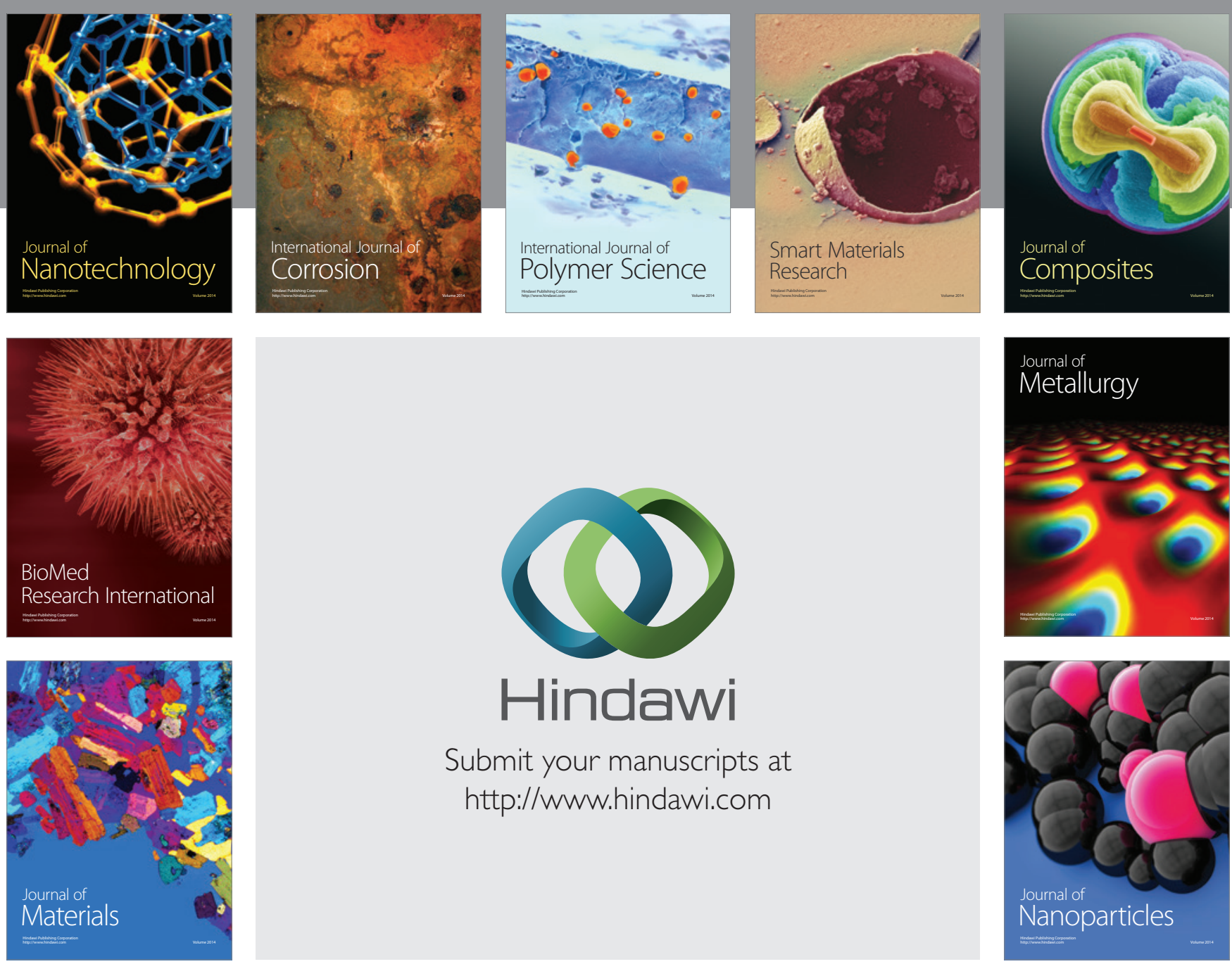

Submit your manuscripts at http://www.hindawi.com
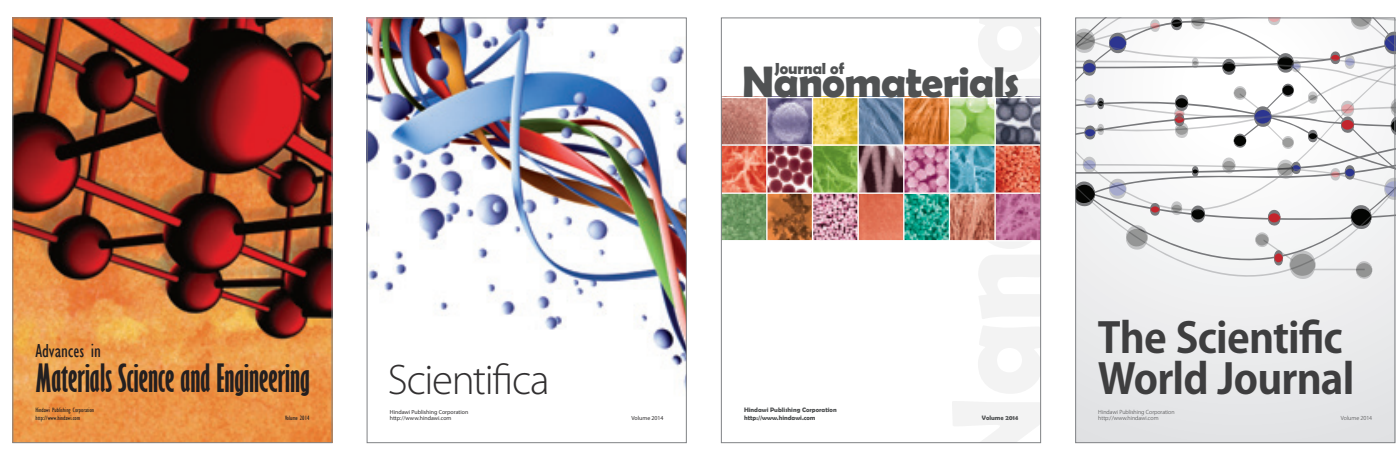

\section{The Scientific World Journal}
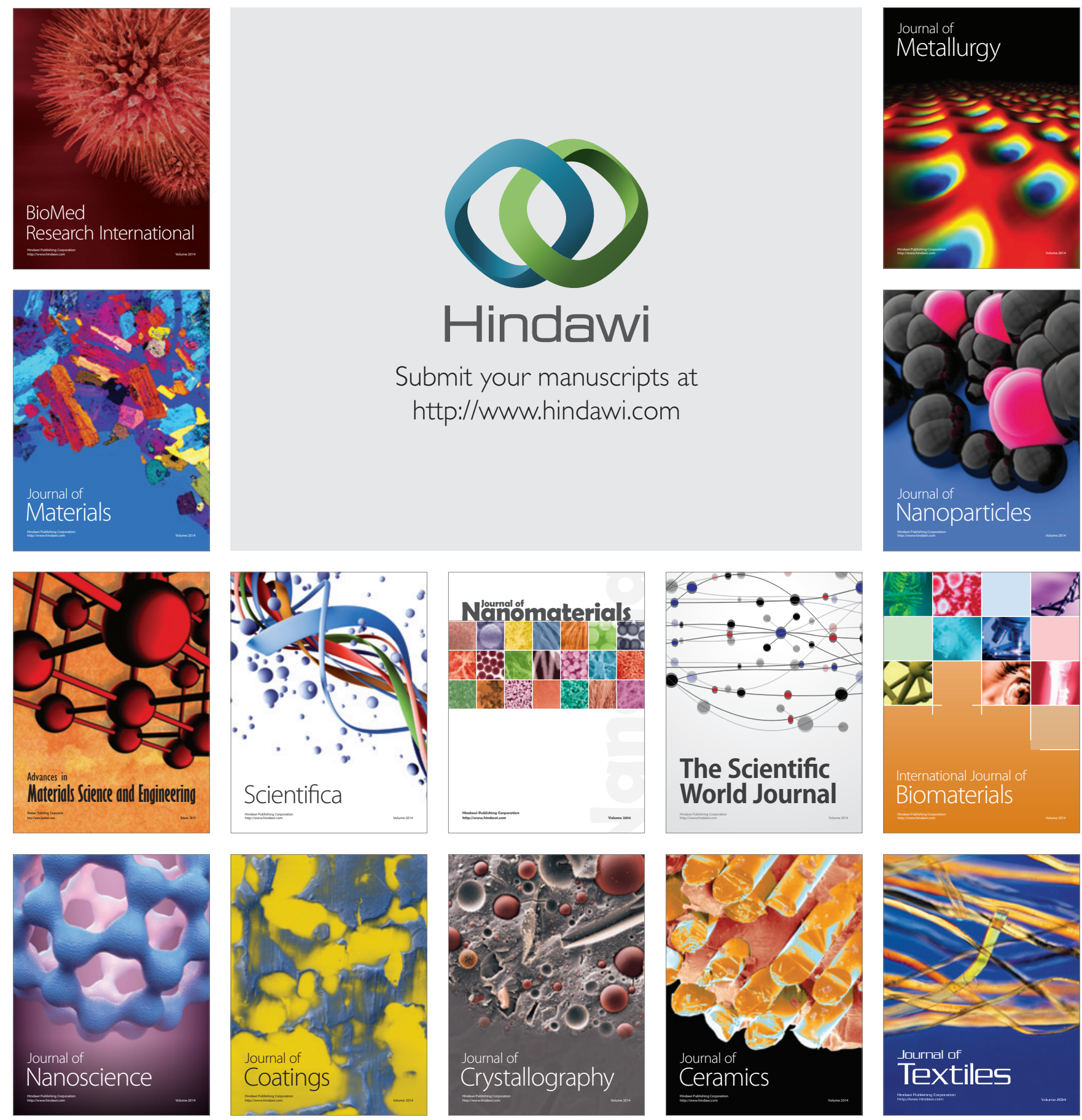